\title{
Mining the data on UTUC management
}

\author{
Michael J. Leveridge, MD, FRCSC
}

Assistant Professor, Departments of Urology and Oncology, Queen's University, Kingston, ON

See related article on page 455 .

Cite as: Can Urol Assoc J 2012;6(6):463-4. http://dx.doi.org/10.5489/cuaj.12340

$\mathrm{T}$ his study by the Canadian Upper Tract Collaboration (CUTC) lays bare the lack of consensus as to the best practices of surgical management of upper tract urothelial carcinoma (UTUC). ${ }^{1}$

The stratification of cases by region here likely does not group patients along any meaningful spectra apart from longitude; each contributing site is a tertiary referral centre, and the regional "groups" each contain variably-sized population centres with dissimilar regional geographies that would tend to erase any disparity of socioeconomic status, ethnicity, provincial health-system constraints (save the Central group of Ontario alone) or carcinogen exposures. Indeed, apparent differences in overall and disease-specific survival between regions are washed out in the multivariable analysis. Age over 65, high pathologic stage and high grade were independent predictors of overall survival.

Very little prospective data of any type exist in the UTUC literature. The CUTC, as well as the similarly monikered multicentered Upper Tract Urothelial Carcinoma Collaboration (UTUCC) and other groups using population-level data, have recently provided significant retrospective insights into the outcomes of nephroureterectomy (NU) that meaningfully add to the evidence base behind the existing guidelines referenced in the paper. ${ }^{2-7}$

In the current study, the differences in surgical technique did not translate to changes in survival endpoints on multivariate analysis, which therefore does not endorse any specific surgical practice. Prior publications, including by the CUTC, have failed to show a survival difference between laparoscopic and open NU. ${ }^{2}$ Canadians are clearly ahead of the curve in the adoption of laparoscopy for UTUC: $53 \%$ of $\mathrm{NU}$ were performed this way in the current study, compared to $28 \%$ in a large prior study. ${ }^{8}$

Management of the distal ureter is similarly up for some debate. Standard practice involves the excision of a cuff of normal bladder, achieved by open or endoscopic means. Oncologic outcomes were not affected by the choice in this study, in keeping with recent published data. ${ }^{9}$ Disturbingly, Ontario population-level data suggest that up to $26 \%$ of patients undergoing NU may have incomplete distal ureteral management, based on measurements of ureteral lengths in pathology specimens. ${ }^{?}$

The question of lymphadenectomy is a challenging one in this setting for multiple reasons. Lymph node involvement has a negative effect on survival in UTUC, although no differences were found between those with node-negative status and those in whom lymphadenectomy was not performed. ${ }^{3}$ Routine performance and extent of lymph node dissection is clearly associated with survival gains in the bladder cancer literature. ${ }^{10}$ The large majority of radical cystectomies, however, are performed with a known diagnosis of muscle invasion (stage $\geq \mathrm{pT} 2$ ), whereas $50.3 \%$ of NU specimens in the current study were for $\mathrm{pT} 1$ disease, and clinical staging remains a significant preoperative challenge. Previous studies have found from $0-6 \%$ node-positivity in T1 disease, compared with $24 \%$ to $35 \%$ for T3 disease. Identifying a significant survival difference in favour of routine lymphadenectomy at the time of NU for all patients would likely require a significant accrual to prospective assessment. The appropriate templates for regional lymphadenectomy to ensure optimal outcomes are not known, though they have been proposed. ${ }^{11}$ Adoption of such templates would mandate a much more significant surgical procedure, likely out of the surgical comfort level of many who currently perform $\mathrm{NU}$, particularly laparoscopically.

As always after such a report, the weary chorus imploring prospective studies grows that much louder. Let's not hold our breath, and instead congratulate UTUC collaborations, such as CUTC and UTUCC, for their efforts in uncovering realities and opportunities in this challenging oncologic space. 
Competing interests: None declared.

This paper has been peer-reviewed.

\section{References}

1. Metcalfe M, Kassouf W, Rendon R, et al. Regional Differences in Practice Patterns and Associated Outcomes for Upper Tract Urothelial Carcinoma in Canada. Can Urol Assoc J 2012;6:455-62. http:// dx.doi.org/10.5489/cuaj.12146

2. Fairey AS, Kassouf W, Estey E, et al. Comparison of oncological outcomes for open and laparoscopic radical nephroureterectomy: results from the Canadian Upper Tract Collaboration. BJU Int 2012 Nov 13. doi: 10.1111/i.1464-410X.2012.11474.x. [Epub ahead of print]

3. Mason RJ, Kassouf W, Bell DG, et al. The Contemporary Role of Lymph Node Dissection During Nephroureterectomy in the Management of Upper Urinary Tract Urothelial Carcinoma: The Canadian Experience. Urology 2012;79:840-5. http://dx.doi.org/10.1016/j.urology.2011.11.058

4. Roscigno M, Shariat SF, Margulis V, et al. Impact of lymph node dissection on cancer specific survival in patients with upper tract urothelial carcinoma treated with radical nephroureterectomy. J Urol 2009;181:2482-9. http://dx.doi.org/10.1016/i.juro.2009.02.021

5. RoscignoM, Shariat SF, Margulis V, et al. The extent of lymphadenectomy seems to be associated with better survival in patients with nonmetastatic upper-tract urothelial carcinoma: how many lymph nodes should be removed? Eur Urol 2009;56:512-9. http://dx.doi.org/10.1016/i.eururo.2009.06.004
6. Lughezzani G, Sun M, Perotte P, et al. Should Bladder cuff Excision Remain the Standard of Care at Nephroureterectomy in Patients with Urothelial Carcinoma of the Renal Pelvis? A Population-based Study. Eur Urol 2010;57:956-62. http://dx.doi.org/10.1016/i.eururo.2009.12.001

7. Abouassaly $\mathrm{R}$, Alibhai $\mathrm{S}$, Shah $\mathrm{N}$, et al. Troubling outcomes from population-level analysis of surgery for upper tract urothelial carcinoma. Urology 2010;76:895-901. http://dx.doi.org/10.1016/i.urology.2010.04.020

8. Capitanio U, Shariat S, Isbarn $\mathrm{H}$, et al. Comparison of oncologic outcomes for open and laparoscopic nephroureterectomy: a multi-institutional analysis of 1249 cases. Eur Urol 2009;56:1-9. http://dx.doi. org/10.1016/i.eururo.2009.03.072

9. Li W-M, Shen J-T, Li C-C, et al. Oncologic Outcomes Following Three Different Approaches to the Distal Ureter and Bladder Cuff in Nephroureterectomy for Primary Upper Urinary Tract Urothelial Carcinoma. Eur Urol 2010;56:963-9. http://dx.doi.org/10.1016/i.eururo.2009.12.032

10. Herr HW, Faulkner JR, Grossman B, et al. Surgical Factors Influence Bladder Cancer Outcomes: a Collaborative Group Report. J Clin Oncol 2004;22:2781-9. http://dx.doi.org/10.1200/JC0.2004.11.024

11. Kondo T, Nakazawa H, Ito F, et al. Primary Site and Incidence of Lymph Node Metastases in Urothelial Carcinoma of Upper Urinary Tract. Urology 2007;69:265-9. http://dx.doi.org/10.1016/i.urology.2006.10.014

12. Roscigno M, Brausi M, Heidenreich A, et al. Lymphadenectomy at the Time of Nephroureterectomy for Upper Tract Urothelial Cancer. Eur Urol 2011;60:776-83. http://dx.doi.org/10.1016/i.eururo.2011.07.009

Correspondence: Dr. Michael Leveridge, Kingston General Hospital, Empire 4, 76 Stuart St., Kingston, 0N K7L 2V7; leveridge@gmail.com 